\title{
Nationwide Distribution of Dengue Virus Type 3 (DENV-3) Genotype I and Emergence of DENV-3 Genotype III during the 2019 Outbreak in Bangladesh
}

\author{
Snigdha Rahman Titir ${ }^{1}$, Shyamal Kumar Paul ${ }^{2}$, Salma Ahmed ${ }^{1}$, Nazia Haque ${ }^{3}$, Syeda Anjuman Nasreen ${ }^{1}$, \\ Khondoker Shoaib Hossain ${ }^{4}$, Fahim Uddin Ahmad ${ }^{5}$, Sultana Shabnam Nila ${ }^{1}$, Jobyda Khanam ${ }^{1}$, Neaz Nowsher ${ }^{6}$,
} Abu Mohammod Mayeenuddin Al Amin ${ }^{7}$, Amdad Ullah Khan ${ }^{8}$, Meiji Soe Aung ${ }^{9}$ (i) and Nobumichi Kobayashi ${ }^{9, *}$

Citation: Titir, S.R.; Paul, S.K.; Ahmed, S.; Haque, N.; Nasreen, S.A.; Hossain, K.S.; Ahmad, F.U.; Nila, S.S. Khanam, J.; Nowsher, N.; et al. Nationwide Distribution of Dengue Virus Type 3 (DENV-3) Genotype I and Emergence of DENV-3 Genotype III during the 2019 Outbreak in Bangladesh. Trop. Med. Infect. Dis. 2021, 6, 58. https://doi.org/10.3390/ tropicalmed6020058

Academic Editor: John McBride

Received: 24 February 2021

Accepted: 19 April 2021

Published: 21 April 2021

Publisher's Note: MDPI stays neutra with regard to jurisdictional claims in published maps and institutional affiliations.

Copyright: (c) 2021 by the authors. Licensee MDPI, Basel, Switzerland. This article is an open access article distributed under the terms and conditions of the Creative Commons Attribution (CC BY) license (https:/ creativecommons.org/licenses/by/ $4.0 /)$
1 Department of Microbiology, Mymensingh Medical College, Mymensingh 2200, Bangladesh; titir.snigdha@gmail.com (S.R.T.); ahmed.salma51@yahoo.com (S.A.); nasreenm19@gmail.com (S.A.N.); nila1081@gmail.com (S.S.N.); dr.jkchaity1986@gmail.com (J.K.)

2 Netrokona Medical College, Netrokona 2400, Bangladesh; drshyamal10@yahoo.com

3 Sheikh Hasina Medical College and Hospital, Jamalpur 1900, Bangladesh; drnaziahaque@gmail.com Department of Endocrinology, BIRDEM Academy, Dhaka 2302, Bangladesh; shoaib.mmc@gmail.com Department of Microbiology, TMSS Medical College, Bogura 5800, Bangladesh; fahim111mmc@gmail.com Department of Pathology, Khulna Medical College, Khulna 9100, Bangladesh; nneazrocky@gmail.com Department of Microbiology, Gazi Medical College, Khulna 9000, Bangladesh; mayeenuddinamin@gmail.com

Department of Medicine, Mymensingh Medical College, Mymensingh 2200, Bangladesh; dramdadukhan@gmail.com

9 Department of Hygiene, Sapporo Medical University School of Medicine, Sapporo 060-8556, Japan; meijisoeaung@sapmed.ac.jp

* Correspondence: nkobayas@sapmed.ac.jp; Tel.: +81-11-611-2111

Abstract: Bangladesh is an endemic region of dengue fever and experienced an unprecedented large outbreak with more than 100,000 confirmed cases in 2019. To understand the prevalence of dengue antibody in patients and molecular epidemiological characteristics of dengue virus (DENV) in this outbreak, a total of 179 blood samples were collected from patients in 10 districts (seven divisions) covering nearly the whole country from August to December 2019. DENV NS-1 was detected in 162 samples, among which DENV-specific IgM was positive in 119 samples (73.5\%), including $60.5 \%$ samples also positive for DENV-specific IgG. Sequencing of the partial C-prM gene and its phylogenetic analysis revealed predominance of DENV type 3 genotype I, accounting for $93 \%$ of samples examined. DENV-3 genotype III was identified in two samples from separate districts, and only one DENV-2 cosmopolitan genotype was found in the capital city, Dhaka. These findings suggest the predominance of DENV-3 genotype I and occurrence of DENV-3 genotype III, associated with increased incidence of recent secondary infection in Bangladesh in 2019.

Keywords: dengue virus; type 3; genotype; IgM; Bangladesh

\section{Introduction}

Dengue virus (DENV) infection is a mosquito-borne, acute systemic disease and has become one of the major public health problems worldwide in the last few decades, with Asia having the greatest disease burden [1]. DENV is a member of the genus Flavivirus of the family Flaviviridae, and it contains four serotypes (DENV-1, -2, -3, and -4) which are further differentiated into genotypes. At present, the WHO Southeast Asia Region is considered hyperendemic for multiple DENV serotypes/genotypes [2]. Although a wide range of clinical manifestations represented by fever are seen in DENV infection in humans, secondary heterotypic DENV infection often results in severe disease previously known as dengue hemorrhagic fever (DHF) or dengue shock syndrome (DSS) [3], which is mediated by antibody-dependent enhancement of disease [4]. While the increased risk of such severe dengue disease is often related to a change in predominant DENV serotypes/genotypes, 
occurrence of DHF/DSS is commonly dependent on DENV types and their sequential order [3]. For example, DHF was associated with secondary infection with DENV-2 Asian genotype, but not with DENV-2 American genotype, after the initial epidemic of DENV-1 in Latin America $[3,5,6]$. This was also supported by the evidence that human sera infected with DENV-1 more efficiently cross-neutralized the DENV-2 American genotype than the Asian genotype [6]. Accordingly, for better control of dengue, it is important to understand its prevalence and monitor circulating DENV types in a population.

In Bangladesh, a large outbreak due to DENV-3 genotype II occurred in 2000 with more than 5000 hospitalized cases and continued until 2002 [2,7,8]. Thereafter, dengue was found at low frequency until 2016, with DENV-2 being recorded as the predominant causative virus, followed by DENV-1 [8-10]. Following the observation of re-emergence of DENV-3, as well as predominance of DENV-2 in 2017 [10-12], a large outbreak of dengue involving more than 10,000 cases occurred in Dhaka, the capital city of Bangladesh, in 2018. This outbreak was caused by multiple viruses including a dominant DENV-2, along with DENV-1 and DENV-3 [8,10,12,13]. A subsequent outbreak in 2019 caused a surge of dengue patients 10 times as high as that of previous year, i.e., 100,201 confirmed cases, among which half of the patients occurred in Dhaka, while the remaining cases were found across the rest of Bangladesh [14,15]. Although DENV-3 was described as predominant in the unprecedented outbreak in 2019 [8], genotypes of the responsible DENV are not yet clarified. The present study was conducted to understand prevalence of secondary dengue infections and reveal genetic characteristics of DENV causing the outbreak, in all areas of Bangladesh. The results indicated a high rate of dengue reinfection, with predominantly DENV-3 genotype I, as well as the emergence of DENV-3 genotype III.

\section{Materials and Methods}

Venous blood samples from febrile patients with clinically suspected dengue were collected from 10 districts in seven divisions in Bangladesh (Figure 1), from August to December 2019. In this year, the number of dengue cases increased from June and reached a peak in August, followed by rapid decrease [16]. Definition of suspected dengue cases included fever of $\geq 38^{\circ} \mathrm{C}$ of less than 7 days duration and two or more symptoms or signs, as well as thrombocytopenia, as described previously [17]. Criteria of sample collection in this study were as follows: patients having fever over $38.5^{\circ} \mathrm{C}$ and serum samples collected within 9 days post symptom onset. Written consent was obtained from individual patients.

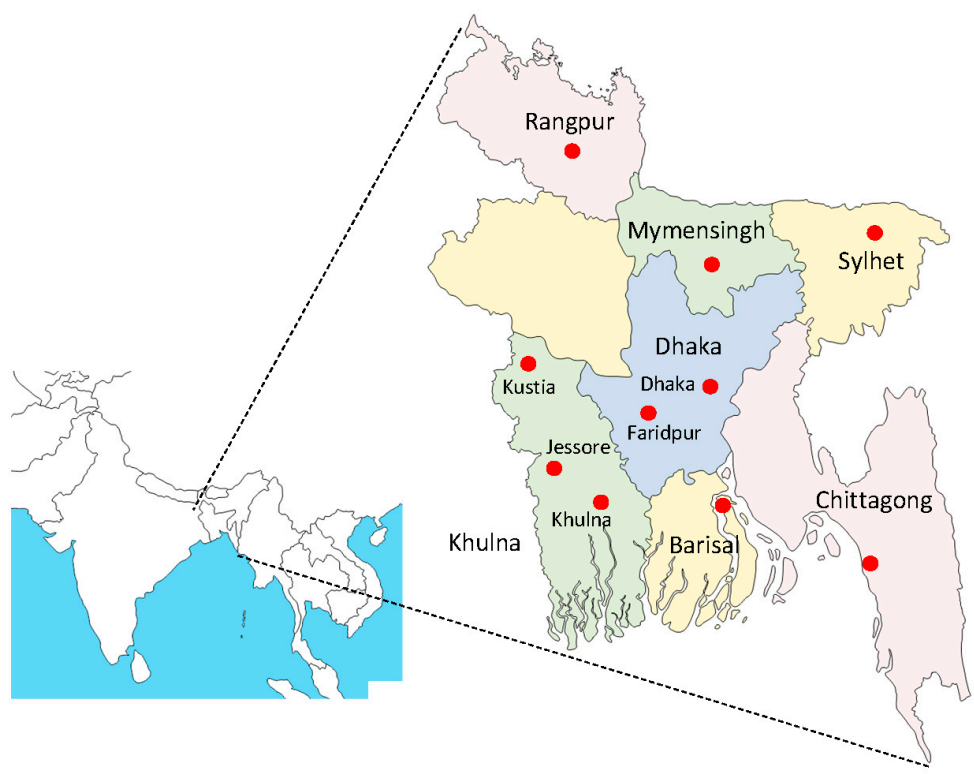

Figure 1. Map of cities in Bangladesh where blood samples were collected from dengue patients in this study. The eight divisions are shown in different colors. 
A flowchart of the analysis of dengue virus antigen, antibody, and gene is shown in Figure 2. Presence of DENV NS1 antigen was tested by the Dengue NS1 Rapid Test Cassette (Acro Biotech Inc., Rancho Cucamonga, CA, USA). Serum samples obtained from the blood samples via centrifugation were further analyzed for antibody and DENV gene.

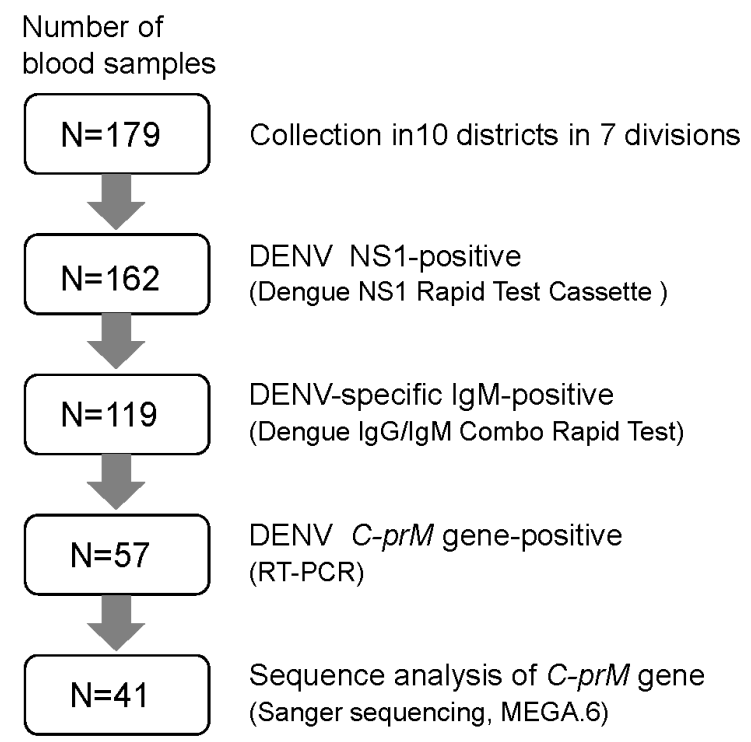

Figure 2. Flowchart representing the study of dengue virus and antibody with the use of blood samples in Bangladesh, 2019.

DENV-specific IgM and IgG antibodies were detected by immunochromatographic test (ICT) using the Dengue IgG/IgM Combo Rapid Test (CTK Biotech, Inc., San Diego, CA, USA) according to the manufacturer's instruction. The partial C-prM gene (511 bp) was amplified by RT-PCR using primer pairs as described previously [18]. Nucleotide sequences of amplified PCR products were determined by Sanger sequencing on an automated sequencer. Using partial C-prM gene sequences in the present study and those retrieved from the GenBank database, a phylogenetic dendrogram of the C-prM gene was constructed using the maximum-likelihood method with the MEGA6 software package (https://megasoftware.net/, accessed on 10 January 2021) [19]. The tree was statistically supported by bootstrapping with 1000 replicates, and genetic distances were calculated using the Kimura two-parameter model. The Clustal Omega program (https://www.ebi.ac.uk/Tools/msa/clustalo/, accessed on 12 January 2021) was also used for multiple alignment of nucleotide/amino-acid sequences and calculation of sequence identity. Partial C-prM gene sequences of representative 16 samples were deposited to GenBank database under accession Nos. MW599404-MW599419.

\section{Results}

A total of 179 blood samples were collected during the study period. Among the patients, males and females accounted for $61.5 \%$ and $38.5 \%$, respectively, and the age range of 15 to 35 years included $48.4 \%$ of all the cases. Approximately $70 \%$ of patients were admitted to hospitals, while the remaining were outpatients. Among 179 samples, 162 $(91 \%)$ were positive for the DENV NS1 antigen. Out of the 162 NS1-positive samples, DENV-specific IgM was detected in 119 samples (73.5\%) by ICT. Both IgM and IgG were detected in 72 samples, accounting for $60.5 \%$ of IgM-positive samples (Table 1). IgMpositive samples were mostly derived in patients with a duration of fever of $>3-5$ days and $>5-7$ days (Figure S1, Supplementary Materials). Three samples were solely IgG-positive, while 40 samples were negative for both IgG and IgM. The DENV C-prM gene was detected in 57 samples. Although positive rates of IgM or C-prM were generally similar in all the 
study sites, divisions/districts with higher IgM-positive rates (>80\%, e.g., Dhaka-Faridpur) showed relatively low RT-PCR-positive rates $(<24 \%)$ (Table 1$)$.

Table 1. Detection of DENV-specific antibody and C-prM gene, as well as assignment of DENV serotype/genotype, in individual divisions/districts.

\begin{tabular}{|c|c|c|c|c|c|}
\hline \multirow{2}{*}{$\begin{array}{l}\text { Division } \\
\text { (District) }\end{array}$} & \multirow{2}{*}{$\begin{array}{c}\text { No. of } \\
\text { NS1-Positive }\end{array}$} & \multicolumn{2}{|c|}{ IgM-Positive (\%) } & \multirow{2}{*}{$\begin{array}{c}\text { RT-PCR Positive } \\
\text { (\%) }\end{array}$} & \multirow{2}{*}{ Serotype (Genotype) * } \\
\hline & & Total & IgM Only/IgM + IgG & & \\
\hline Barisal & 22 & $16(72.7)$ & $4(18.2) / 12(54.5)$ & $10(45.5)$ & DENV-3 (I) \\
\hline Chittagong & 18 & $14(77.8)$ & $7(38.9) / 7(38.9)$ & $7(38.9)$ & DENV-3 (I) \\
\hline Dhaka & 40 & $27(67.5)$ & $7(17.5) / 20(50)$ & $18(45)$ & $\begin{array}{c}\text { DENV-2 (Cosmopolitan), } \\
\text { DENV-3 (I) }\end{array}$ \\
\hline $\begin{array}{c}\text { Dhaka } \\
\text { (Faridpur) }\end{array}$ & 11 & $9(81.8)$ & $4(36.4) / 5(45.5)$ & $2(18.2)$ & DENV-3 (III) \\
\hline Khulna & 16 & $9(56.3)$ & $5(31.3) / 4(25)$ & $6(37.5)$ & DENV-3 (I, III) \\
\hline $\begin{array}{l}\text { Khulna } \\
\text { (Jessore) }\end{array}$ & 10 & $7(70)$ & $4(40) / 3(30)$ & $2(20)$ & DENV-3 (I) \\
\hline $\begin{array}{l}\text { Khulna } \\
\text { (Kustia) }\end{array}$ & 12 & $9(75)$ & $4(33.3) / 5(41.7)$ & $4(33.3)$ & DENV-3 (I) \\
\hline Mymensingh & 10 & $8(80)$ & $3(30) / 5(50)$ & $3(30)$ & DENV-3 (I) \\
\hline Rangpur & 13 & $11(84.6)$ & $3(23.1) / 8(61.5)$ & $3(23.1)$ & DENV-3 (I) \\
\hline Sylhet & 10 & $9(90)$ & $6(60) / 3(30)$ & $2(20)$ & DENV-3 (I) \\
\hline Total & 162 & $119(73.5)$ & $47(29.0) / 72(44.4)$ & $57(35.2)$ & \\
\hline
\end{tabular}

* Serotypes were assigned to 41 samples. Genotype was classified by phylogenetic analysis (Figure 3a,b).

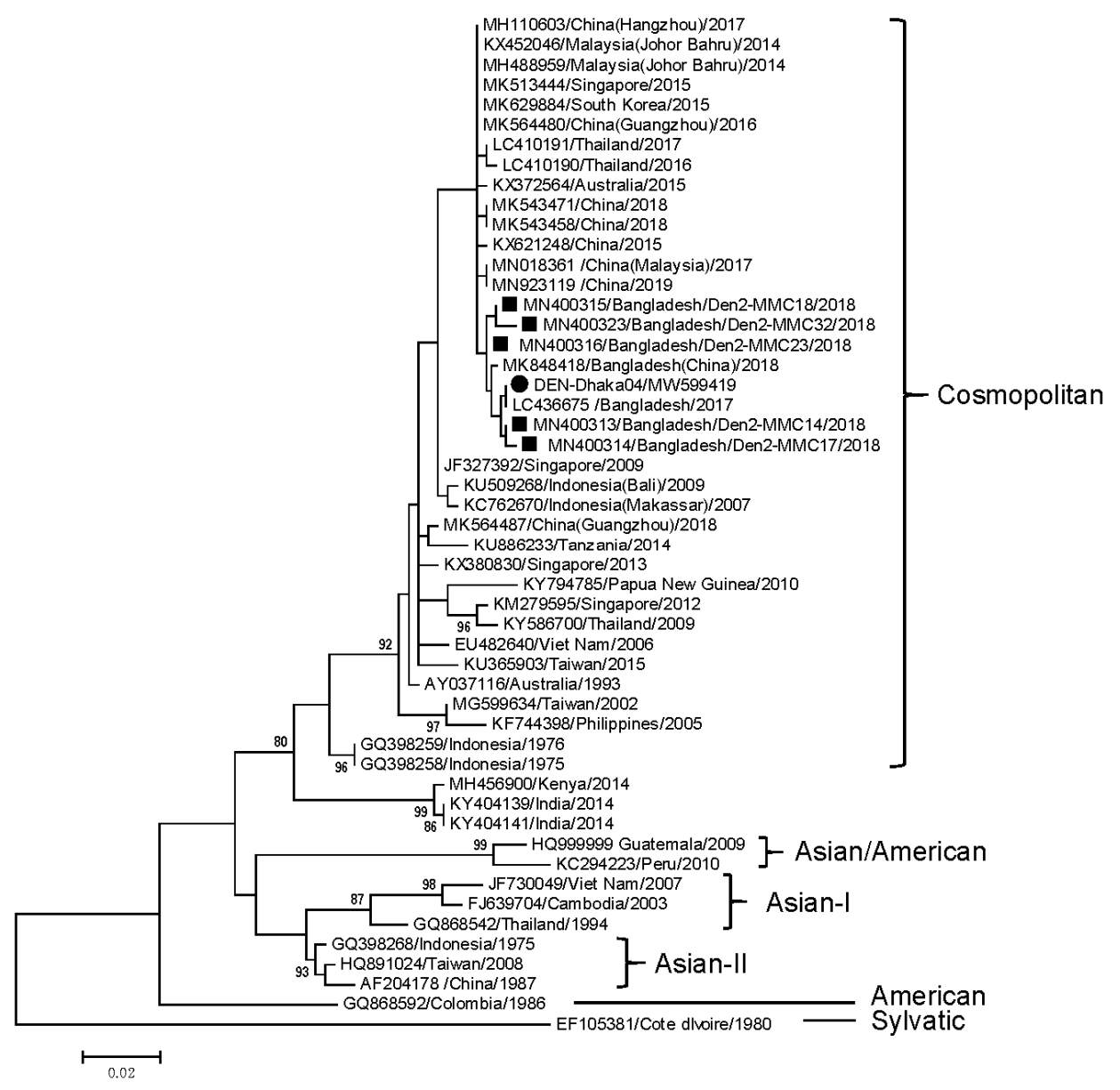

(a)

Figure 3. Cont. 


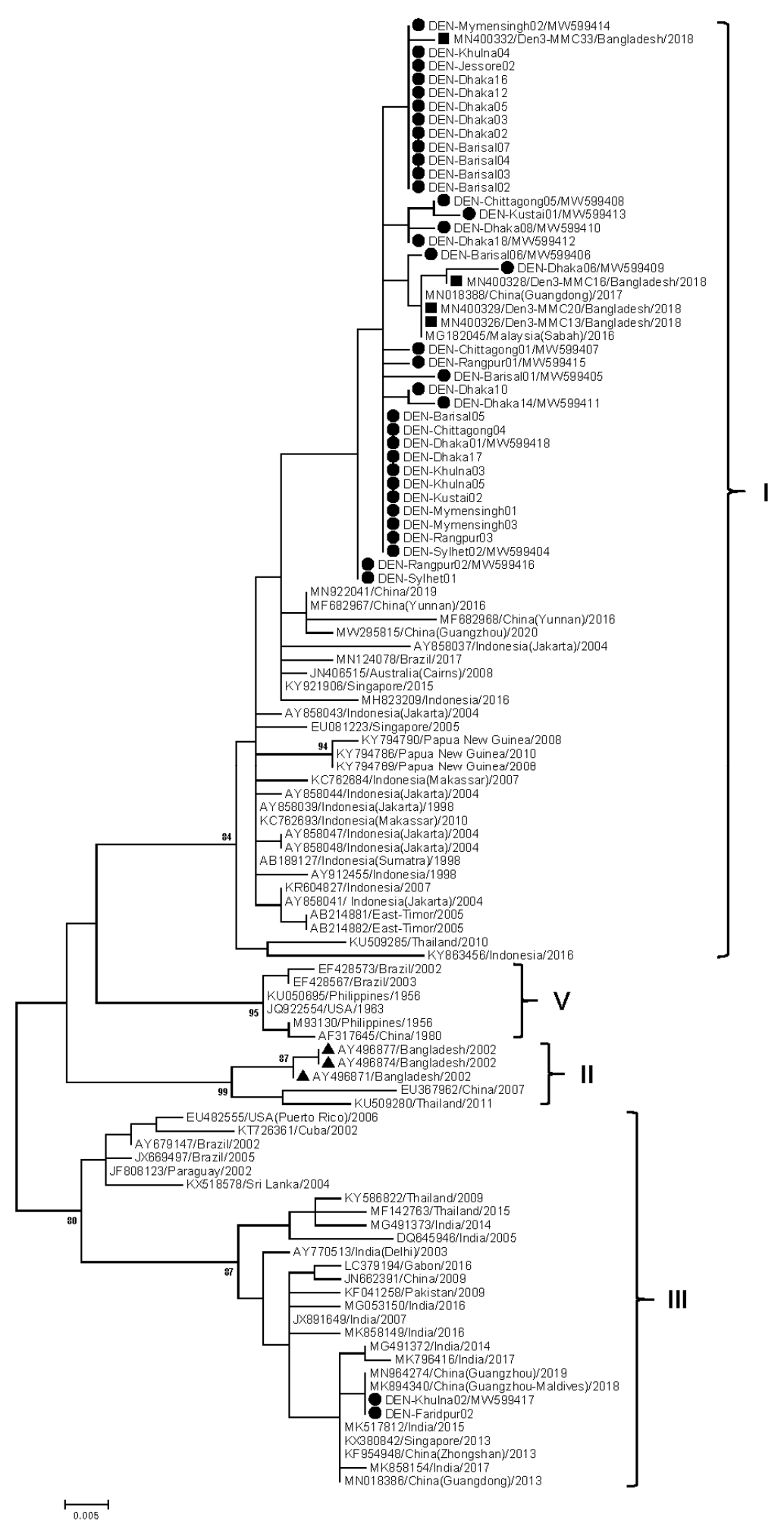

(b)

Figure 3. Phylogenetic dendrogram of partial C-prM gene of DENV-2 (a) and DENV-3 (b) in Bangladesh in 2019 outbreak and other diverse geographical locations, constructed using the maximum-likelihood method with the MEGA6 software package. Variation scale is described at the bottom. Percentage bootstrap support is indicated by the values at each node (values $<80 \%$ were omitted). Closed circles and squares indicate DENV-2/DENV-3 in the present study (2019) and those reported previously (2018) in Dhaka [13], respectively. Triangles represent DENV-3 strains detected in Bangladesh in 2002. Genotypes of DENV-3/DENV-2 are shown on the right. Two DENV-3 samples were not included in dendrogram (b) because their nucleotide sequence length was considerably shorter than other sequences. 
Although sequencing of partial C-prM gene was attempted for all 57 samples, accurate sequence data were obtained from 41 samples, after removal of samples showing lowquality data. Among the 41 samples, 40 samples belonged to DENV-3, while only one belonged to DENV-2. Phylogenetic analysis of C-prM genes revealed that most of DENV-3 belonged to genotype I, closely related to DENV-3 in Dhaka in 2018, as well as to recent strains in China and Malaysia (Figure 3b). Only two DENV-3 samples from Khulna and Faridpur (Dhaka division) were assigned to genotype III and clustered with strains in China, India, and Singapore detected after 2013. The partial C-prM gene sequences of genotype I DENV-3 exhibited $>99 \%$ identity to each other, while they showed $93 \%$ identity to genotype III (data not shown). In the deduced C-prM amino-acid sequence, eight amino acids were distinct between genotype I and III (Figure S2, Supplementary Materials). Two cases of genotype III DENV-3 had identical nucleotide and amino acid sequences. Only one DENV-2 sample was detected in Dhaka, and it belonged to the Cosmopolitan genotype, being mostly close to DENV-2 in Dhaka, 2018 (Figure 3a).

\section{Discussion}

Expansion of the dengue outbreak in Bangladesh since 2017 is considered relevant to the introduction of DENV-3 into the region where preexisting DENV-1 and DENV-2 were circulating [11-13]. While having a low rate in 2017, DENV-3 showed a similar prevalence to DENV-2 in 2018 [13]. Our present study indicates that DENV-3 became predominant, displacing other DENV serotypes in 2019, when an unexpected large outbreak occurred in Bangladesh. Such a switching of major DENV serotype was described as involved in periodical outbreaks in endemic regions [20,21]. In western India, the dengue outbreak in 2017 was described as being associated with the replacement of dominant DENV-2 by emerging DENV-3 [22], which seems to be a similar situation to Bangladesh.

While DENV-3 re-emerged as a predominant virus after a 15 year period in Bangladesh, genotype I was predominant in 2018 and 2019, unlike genotype II that was prevalent in 2002 [23]. It is notable in the present study that two cases of DENV-3 with genotype III were identified, for the first time in Bangladesh. DENV-3 genotypes I and II have been prevalent in Asia, while genotype III is distributed across wider regions, i.e., Asia, the Caribbean, the Americas, and Europe [24]. Evidence from phylogenetic analysis suggests that genotype III DENV-3 in Bangladesh might have been brought in from neighboring countries, e.g., India or China. Furthermore, the two cases of genotype III DENV-3 had identical partial C-prM gene sequences, but they were detected in different districts, suggesting its potential spread within the country. Co-circulation of two DENV-3 genotypes I and III was reported in Colombia [25] and Malaysia [26]. Nevertheless, in Malaysia, an apparent shift from genotype III (2014-2015) to genotype I (2016-2017) was observed [26], which was different from the change in Bangladesh. Notably, genotype III viruses acquiring mutations were found to be associated with outbreaks in western India [22]. Although detailed genetic features in genotype III DENV-3 from Bangladesh remain to be determined, its prevalence should be carefully monitored, because switching of the main lineage even within the same serotype was found to be associated with outbreak [27]. Regarding DENV-2, crossneutralization capability by antisera from individuals infected with DENV-1 was revealed to be different depending on genotypes [6]. Thus, it is also possible that the emerging genotype of DENV-3 may become dominant by selection with a preexisting antibody in the population. Nevertheless, it should be also noted that the introduction of new genotypes does not necessarily mean its growing prevalence in the population, because spread of new genotypes may depend on the transmissibility (from humans to mosquitoes, and vice versa), vector competence, and other environmental factors.

In the present study, DENV-specific IgM was detected in 73.5\% of DENV-NS1-positive serum samples, among which $60 \%$ were positive for IgG. Because in this study, approximately $80 \%$ of blood samples were obtained within 7 days of febrile state, the concomitant detection of IgM and IgG may be suggestive of recent secondary infection on the basis of the timeline of dengue biomarkers [28]. The putative secondary infection rate was 
comparable to that described from global outbreak data (62\%) [29]. Prevalence of IgG was generally similar among all the study sites including Dhaka, while previous major outbreaks appeared to take place mostly in Dhaka [9,11-13]. This may imply that dengue might have been potentially prevalent across the country. The relatively lower RT-PCRpositive rates associated with higher IgM-positive rates in some study sites suggest that DENV in the bloodstream was mostly neutralized by antibody and disposed of when blood samples were collected.

Secondary infection with DENV-2, DENV-3, and DENV-4, as well as primary infection with DENV-3, was shown to increase the risk of severe dengue disease [30]. In a recent study in northern Bangladesh, the rate of severe dengue was documented as $5.9 \%$ of patients, although the incidence of secondary infection was considerably lower than that of primary infection [31]. The predominance of DENV-3, emergence of its novel genotype III, and potentially high rate of secondary infection may pose a concern for the increased prevalence of dengue and its burden in Bangladesh. Hence, persistent molecular epidemiological surveillance of DENV may be valuable for the prevention and control of dengue outbreaks.

Supplementary Materials: The following are available online at https: / www.mdpi.com/article/ 10.3390/tropicalmed6020058/s1: Figure S1. Detection of DENV-specific IgM and IgG by ICT and C-prM gene by RT-PCR in different periods (days) of fever; Figure S2. Alignment of partial C-prM amino-acid sequences of DENV-3 performed by Clustal Omega.

Author Contributions: Conceptualization, S.R.T., S.A.N., and S.K.P.; methodology, S.R.T., S.A., and N.H.; investigation, S.R.T. and N.K.; resources, K.S.H., F.U.A., S.S.N., J.K., N.N., A.M.M.A.A., and A.U.K.; data curation, M.S.A.; writing-original draft preparation, S.R.T.; writing-review and editing, N.K.; supervision, S.A.N. and S.K.P. All authors have read and agreed to the published version of the manuscript.

Funding: This research received no external funding.

Institutional Review Board Statement: The study was conducted according to the guidelines of the Declaration of Helsinki and approved by the Institutional Review Board of Mymensingh Medical College.

Informed Consent Statement: Written informed consent was obtained from all the patients involved in the study to use blood samples for serological and genetic analysis of DENV.

Acknowledgments: We are grateful to Istiaque Mahmud (Chittagong Medical College), Rezwan Kaiser (Sher-e-Bangla Medical College, Barisal), M.A. Aziz (Rangpur Medical college), and Mohammod Golam Mortuza (Mymensingh Medical College) for cooperation with sample collection.

Conflicts of Interest: The authors declare no conflict of interest.

\section{References}

1. Bhatt, S.; Gething, P.W.; Brady, O.J.; Messina, J.P.; Farlow, A.W.; Moyes, C.L.; Drake, J.M.; Brownstein, J.S.; Hoen, A.G.; Sankoh, O.; et al. The global distribution and burden of dengue. Nature 2013, 496, 504-507. [CrossRef]

2. Tsheten, T.; Gray, D.J.; Clements, A.C.A.; Wangdi, K. Epidemiology and challenges of dengue surveillance in the WHO South-East Asia Region. Trans. R Soc. Trop. Med. Hyg. 2021. [CrossRef] [PubMed]

3. Guzman, M.G.; Alvarez, M.; Halstead, S.B. Secondary infection as a risk factor for dengue hemorrhagic fever/dengue shock syndrome: An historical perspective and role of antibody-dependent enhancement of infection. Arch. Virol. 2013, 158, 1445-1459. [CrossRef] [PubMed]

4. Bhatt, P.; Sabeena, S.P.; Varma, M.; Arunkumar, G. Current Understanding of the Pathogenesis of Dengue Virus Infection. Curr. Microbiol. 2021, 78, 17-32. [CrossRef]

5. Rico-Hesse, R.; Harrison, L.M.; Salas, R.A.; Tovar, D.; Nisalak, A.; Ramos, C.; Boshell, J.; de Mesa, M.T.; Nogueira, R.M.; da Rosa, A.T. Origins of dengue type 2 viruses associated with increased pathogenicity in the Americas. Virology 1997, 230, $244-251$. [CrossRef]

6. Kochel, T.J.; Watts, D.M.; Halstead, S.B.; Hayes, C.G.; Espinoza, A.; Felices, V.; Caceda, R.; Bautista, C.T.; Montoya, Y.; Douglas, S.; et al. Effect of dengue-1 antibodies on American dengue-2 viral infection and dengue haemorrhagic fever. Lancet 2002, 360, 310-312. [CrossRef] 
7. Podder, G.; Breiman, R.F.; Azim, T.; Thu, H.M.; Velathanthiri, N.; Mai, L.Q.; Lowry, K.; Aaskov, J.G. Origin of dengue type 3 viruses associated with the dengue outbreak in Dhaka, Bangladesh, in 2000 and 2001. Am. J. Trop. Med. Hyg. 2006, 74, $263-265$. [CrossRef] [PubMed]

8. Riad, M.H.; Cohnstaedt, L.W.; Scoglio, C.M. Risk Assessment of Dengue Transmission in Bangladesh Using a Spatiotemporal Network Model and Climate Data. Am. J. Trop. Med. Hyg. 2021. [CrossRef]

9. Muraduzzaman, A.K.M.; Alam, A.N.; Sultana, S.; Siddiqua, M.; Khan, M.H.; Akram, A.; Haque, F.; Flora, M.S.; Shirin, T. Circulating dengue virus serotypes in Bangladesh from 2013 to 2016. Virusdisease 2018, 29, 303-307. [CrossRef]

10. Ahsan, A.; Haider, N.; Kock, R.; Benfield, C. Possible Drivers of the 2019 Dengue Outbreak in Bangladesh: The Need for a Robust Community-Level Surveillance System. J. Med. Entomol. 2021, 58, 37-39.

11. Suzuki, K.; Phadungsombat, J.; Nakayama, E.E.; Saito, A.; Egawa, A.; Sato, T.; Rahim, R.; Hasan, A.; Lin, M.Y.; Takasaki, T.; et al. Genotype replacement of dengue virus type 3 and clade replacement of dengue virus type 2 genotype Cosmopolitan in Dhaka, Bangladesh in 2017. Infect. Genet. Evol. 2019, 75, 103977. [CrossRef] [PubMed]

12. Shirin, T.; Muraduzzaman, A.K.M.; Alam, A.N.; Sultana, S.; Siddiqua, M.; Khan, M.H.; Akram, A.; Sharif, A.R.; Hossain, S.; Flora, M.S. Largest dengue outbreak of the decade with high fatality may be due to reemergence of DEN-3 serotype in Dhaka, Bangladesh, necessitating immediate public health attention. New Microbes New Infect. 2019, 29, 100511. [CrossRef] [PubMed]

13. Ahmad, F.U.; Paul, S.K.; Aung, M.S.; Mazid, R.; Alam, M.; Ahmed, S.; Haque, N.; Hossain, M.A.; Paul, S.; Sharmin, R.; et al. Co-circulation of dengue virus type 3-genotype I and type 2-Cosmopolitan genotype in 2018 outbreak in Dhaka, Bangladesh. New Microbes New Infect. 2019, 33, 100629. [CrossRef]

14. Hsan, K.; Hossain, M.M.; Sarwar, M.S.; Wilder-Smith, A.; Gozal, D. Unprecedented rise in dengue outbreaks in Bangladesh. Lancet Infect. Dis. 2019, 19, 1287. [CrossRef]

15. Hossain, M.S.; Siddiqee, M.H.; Siddiqi, U.R.; Raheem, E.; Akter, R.; Hu, W. Dengue in a crowded megacity: Lessons learnt from 2019 outbreak in Dhaka, Bangladesh. PLoS Negl. Trop. Dis. 2020, 14, e0008349. [CrossRef]

16. Start Network. Dhaka, Bangladesh: Dengue Outbreak-Anticipatory Briefing Note-27 April 2020. Available online: https: / / reliefweb.int/report/bangladesh/dhaka-bangladesh-dengue-outbreak-anticipatory-briefing-note-27-april-2020 (accessed on 31 January 2021).

17. Ho, T.S.; Wang, S.M.; Lin, Y.S.; Liu, C.C. Clinical and laboratory predictive markers for acute dengue infection. J. Biomed. Sci. 2013, 20, 75. [CrossRef] [PubMed]

18. Lanciotti, R.S.; Calisher, C.H.; Gubler, D.J.; Chang, G.J.; Vorndam, A.V. Rapid detection and typing of dengue viruses from clinical samples by using reverse transcriptase-polymerase chain reaction. J. Clin. Microbiol. 1992, 30, 545-551. [CrossRef]

19. Tamura, K.; Stecher, G.; Peterson, D.; Filipski, A.; Kumar, S. MEGA6: Molecular Evolutionary Genetics Analysis version 6.0. Mol. Biol. Evol. 2013, 30, 2725-2729. [CrossRef]

20. Rajarethinam, J.; Ang, L.W.; Ong, J.; Ycasas, J.; Hapuarachchi, H.C.; Yap, G.; Chong, C.S.; Lai, Y.L.; Cutter, J.; Ho, D.; et al. Dengue in Singapore from 2004 to 2016: Cyclical Epidemic Patterns Dominated by Serotypes 1 and 2. Am. J. Trop. Med. Hyg. 2018, 99, 204-210. [CrossRef] [PubMed]

21. Carreño, M.F.; Jiménez-Silva, C.L.; Rey-Caro, L.A.; Conde-Ocazionez, S.A.; Flechas-Alarcón, M.C.; Velandia, S.A.; Ocazionez, R.E. Dengue in Santander State, Colombia: Fluctuations in the prevalence of virus serotypes are linked to dengue incidence and genetic diversity of the circulating viruses. Trop. Med. Int. Health 2019, 24, 1400-1410. [CrossRef] [PubMed]

22. Patil, J.A.; Alagarasu, K.; Kakade, M.B.; More, A.M.; Gadekar, K.A.; Jadhav, S.M.; Parashar, D.; Shah, P.S. Emergence of dengue virus type 1 and type 3 as dominant serotypes during 2017 in Pune and Nashik regions of Maharashtra, Western India. Infect. Genet. Evol. 2018, 66, 272-283. [CrossRef] [PubMed]

23. Islam, M.A.; Ahmed, M.U.; Begum, N.; Chowdhury, N.A.; Khan, A.H.; Parquet Mdel, C.; Bipolo, S.; Inoue, S.; Hasebe, F.; Suzuki, Y.; et al. Molecular characterization and clinical evaluation of dengue outbreak in 2002 in Bangladesh. Jpn. J. Infect. Dis. 2006, 59, 85-91.

24. Waman, V.P.; Kale, M.M.; Kulkarni-Kale, U. Genetic diversity and evolution of dengue virus serotype 3: A comparative genomics study. Infect. Genet. Evol. 2017, 49, 234-240. [CrossRef]

25. Usme-Ciro, J.A.; Mendez, J.A.; Tenorio, A.; Rey, G.J.; Domingo, C.; Gallego-Gomez, J.C. Simultaneous circulation of genotypes I and III of dengue virus 3 in Colombia. Virol. J. 2008, 5, 101. [CrossRef] [PubMed]

26. Suppiah, J.; Ching, S.M.; Amin-Nordin, S.; Mat-Nor, L.A.; Ahmad-Najimudin, N.A.; Low, G.K.; Abdul-Wahid, M.Z.; Thayan, R.; Chee, H.Y. Clinical manifestations of dengue in relation to dengue serotype and genotype in Malaysia: A retrospective observational study. PLoS Negl. Trop. Dis. 2018, 12, e0006817. [CrossRef]

27. Lee, K.S.; Lai, Y.L.; Lo, S.; Barkham, T.; Aw, P.; Ooi, P.L.; Tai, J.C.; Hibberd, M.; Johansson, P.; Khoo, S.P.; et al. Dengue virus surveillance for early warning, Singapore. Emerg. Infect. Dis. 2010, 16, 847-849. [CrossRef] [PubMed]

28. Muller, D.A.; Depelsenaire, A.C.; Young, P.R. Clinical and Laboratory Diagnosis of Dengue Virus Infection. J. Infect. Dis. 2017, 215 (Suppl. 2), S89-S95. [CrossRef]

29. Guo, C.; Zhou, Z.; Wen, Z.; Liu, Y.; Zeng, C.; Xiao, D.; Ou, M.; Han, Y.; Huang, S.; Liu, D.; et al. Global Epidemiology of Dengue Outbreaks in 1990-2015: A Systematic Review and Meta-Analysis. Front. Cell Infect. Microbiol. 2017, 7, 317. [CrossRef] 
30. Soo, K.M.; Khalid, B.; Ching, S.M.; Chee, H.Y. Meta-Analysis of Dengue Severity during Infection by Different Dengue Virus Serotypes in Primary and Secondary Infections. PLoS ONE 2016, 11, e0154760. [CrossRef]

31. Rafi, A.; Mousumi, A.N.; Ahmed, R.; Chowdhury, R.H.; Wadood, A.; Hossain, G. Dengue epidemic in a non-endemic zone of Bangladesh: Clinical and laboratory profiles of patients. PLoS Negl. Trop. Dis. 2020, 14, e0008567. [CrossRef] 